\title{
The Effect of Epidural Levobupivacaine and Fentanyl on Stress Response and Pain Management in Patients Undergoing Percutaneous Nephrolithotomy
}

A Ahiskalioglu, EO Ahiskalioglu, A Dostbil, A Can, M Aksoy, M Celik, I Ince, H Kursad

\begin{abstract}
Objective: The perioperative stress response of patients who were planned to have percutaneous nephrolithotomy under epidural anesthesia with opioids and local anesthetics has not been investigated in detail yet. Our hypothesis is that the stress response following percutaneous nephrolithotomy can be lessened by epidural analgesia.

Methods: A total of 48 patients, between 18-65 years of age and ASA I-II, in whom elective percutaneous nephrolithotomy was planned, were randomly divided into two groups as follows. Group GA $(\mathrm{n}=24)$ : general anesthesia by sevoflurane and fentanyl and postoperative intravenous PCA; Group GE $(n=24)$ : epidural anesthesia and general anesthesia together with postoperative epidural analgesia ( $0.125 \%$ levobupivacaine+fentanyl). Blood levels for glucose, insulin, prolactin and cortisol were evaluated prior to anesthesia, after surgical incision, immediately following percutaneous dilatation and postoperative $24^{\text {th }}$ hour. Intraoperative hemodynamic parameters and postoperative pain scores together with preoperative and postoperative hematocrit values were recorded.
\end{abstract}

Results: Postoperative pain scores were found to be statistically significantly lower $(p<0.05)$ in Group GE at all measurement times. Intraoperative blood loss was statistically significantly lower in Group GE $(p=0.011)$. When hemodynamic parameters were compared, at all time intervals except baseline measurement, blood pressure and heart rate were significantly lower in Group GE $(p<0.05)$. Levels of stress hormones, glucose, cortisol, insulin and prolactin remained significantly lower in Group GE.

Conclusion: We think that epidural anesthesia, performed in addition to general anesthesia, may be a comfortable anesthesia method with its suppressive effects on intraoperative and postoperative stress response together with reduced pain scores in the postoperative period.

Keywords: Epidural analgesia, levobupivacaine, percutaneous nephrolithotomy, surgical stress response

From: Ataturk University School of Medicine, Department of Anesthesiology and Reanimation 25100, Yakutiye/Erzurum/Turkey.

Correspondence: Professor A Ahiskalioglu, Ataturk University School of Medicine, Department of Anesthesiology and Reanimation 25100, Yakutiye /Erzurum/ Turkey.

Email: aliahiskalioglu@hotmail.com 


\section{INTRODUCTION}

Stress response is the union of a series of autonomic, neuro-endocrine, metabolic and immune responses, initiated by various noxious stimulants, aiming to protect the homeostasis of the body against them (1).

Hormones secreted by the endocrine system, especially pituitary, thyroid, parathyroid, pancreas and adrenal glands, are important in terms of creating a response when anesthesia and surgery are performed. The pituitary gland is stimulated by hypothalamic regulatory hormones secreted by the hypothalamus. While concentrations of catabolic hormones such as cortisol, glucagon and catecholamines are elevated by the hormones secreted by the pituitary gland, concentrations of anabolic hormones such as insulin and testosterone are reduced. The necessity of using methods which can reduce the stress response of the organism to surgery is gaining more importance in determining the method for anesthesia and surgery (2-4).

Although anesthesia and surgery can individually cause endocrine and metabolic changes by creating stress, these responses can be reduced, even avoided, by implementing different anesthetic methods. For this purpose, to reduce the stress response, various methods have been developed. Among these methods, the combination of epidural and general anesthesia has been in use extensively for the last ten years for major abdominal, orthopedic and thoracic interventions.

Parallel to the technological improvements in the field of medicine, percutaneous nephrolithotomy (PNL) which is a noninvasive procedure became the preferred method against open surgery for management of renal stones (5).

The advantages of percutaneous technique are less postoperative pain, a smaller wound scar and a shorter hospital stay (6). However, despite all of the advantages of percutaneous nephrolithotripsy, bleeding, infection, fluid and electrolyte disorders may occur; recurrent interventions and irrigation of the kidney may result in various chemical, 
hemodynamic and hormonal changes (7-9). The comparative data on these changes have not been investigated in detail yet (10).

Our hypothesis was that the stress response following PNL can be lessened by intraoperative and postoperative epidural anesthesia/analgesia. The aim of this randomized prospective study was to assess the efficiency of two different methods of anesthesia on endocrine and metabolic responses of patients undergoing PNL.

\section{MATERIALS AND METHODS}

Following approval by the Ethics Committee, this study was conducted as a randomized and prospective study. Informed written consents of all patients involved in the study were obtained. Inclusion criteria to the study were as follows: (1) planned elective PNL in morning hours (9:00-11:00) (2) in I-II ASA (American Society of Anesthesiologists) risk classification groups during preanesthetic evaluation (3) ages between 18-65 years (4) no history of chronic pain or opioid use. The patients excluded from the study were as follows: Diabetes mellitus, arterial hypertension, congestive heart failure, psychiatric disorder, history of drug allergy or allergy against amide-type local anesthetics, bacteremia, endocrine and metabolic disorders, having clear contraindications in terms of epidural intervention, history of narcotic or nonnarcotic analgesic drug use in the last 24 hours, drug or alcohol addiction.

\section{Randomization:}

On the morning of operation, by using computer randomization software, the patients were randomized and divided into two groups as follows: Group GA, general anesthesia followed by postoperative patient-controlled analgesia; Group GE, combined general/epidural anesthesia followed by postoperative epidural analgesia. 


\section{Anesthesia Technique:}

Due to the circadian rhythm of the stress hormone levels, operations of the patients were performed in the morning hours (9:00-11:00 am) and only the first case of that day was included in the study.

Group GA: For induction of anesthesia, $2 \mathrm{mg} / \mathrm{kg}$ propofol (Propofol ${ }^{\circledR}$, Fresenius Kabi, Germany) IV and for muscle relaxation $0.6 \mathrm{mg} / \mathrm{kg}$ rocuronium (Esmeron ${ }^{\circledR}$, Glaxo Smith Kline, UK) IV were used. When necessary, $0.1 \mathrm{mg} / \mathrm{kg}$ rocuronium was used throughout the surgery for muscle relaxation. Following endotracheal intubation, anesthesia was maintained by $1.5 \%$ sevoflurane (Sevorane ${ }^{\circledR}$, Abbott, USA), $50 \mathrm{mcg} / \mathrm{hr}$ fentanyl, $50 \% \mathrm{~N}_{2} \mathrm{O}$ in oxygen, and $50 \% \mathrm{O}_{2}$ in air (Tidal Volume $=6-8 \mathrm{ml} / \mathrm{kg}$, frequency $=10 / \mathrm{min}$ ). During operation, fentanyl $1 \mathrm{mcg} / \mathrm{kg}$ was administered as an additional anesthetic dose if sudden increases in heart rate and MAP did not respond to a 50\% increase in gas concentration.

Group GE (General Anesthesia + Epidural Anesthesia Group): In Group GE, before induction of anesthesia, after taking necessary precautions of asepsis-antisepsis, infiltration anesthesia was performed by administering $3 \mathrm{ml}$ of $2 \%$ lidocaine subcutaneously, in sitting position. With a median approach through intervertebral spaces T11-T12 or T12-L1, an $18 \mathrm{G}$ Tuohy epidural needle was advanced with its opening in the cephalic direction and epidural space was defined by the "negative pressure hanging drop" technique. After being ensured that there was no blood or CCF coming out, $2 \mathrm{ml}(40 \mathrm{mg})$ lidocaine was administered as a test dose. $0.125 \%$ Levobupivacaine was administered in $10-15 \mathrm{ml}$ of bolus doses, together with 2 mcg / ml fentanyl. By following the level of sensory block with the hot-cold method in bilateral midclavicular lines, it was waited to rise up to T6. Intraoperative analgesia was provided by administering $10 \mathrm{ml} / \mathrm{hr} 0.125$ levobupivacaine $+2 \mathrm{mcg} / \mathrm{ml}$ through the epidural catheter. When analgesia reached satisfactory level, general anesthesia was performed. The same protocol was used and endotracheal intubation was made in Group GA. Following 
endotracheal intubation, anesthesia was maintained by $1.5 \%$ sevoflurane, $50 \% \mathrm{~N}_{2} \mathrm{O}$ in oxygen, and $50 \% \mathrm{O}_{2}$ in air.

\section{Postoperative Analgesia:}

In Group GA, postoperative analgesia was provided by patient-controlled analgesia using fentanyl. PCA device was set as follows: loading dose of $1.5 \mathrm{mcg} / \mathrm{kg}$; bolus dose of $25 \mathrm{mcg}$; lockout time 10 minutes; total infusion dose of $400 \mathrm{mcg} ; 4$ hour-limit.

In Group GE, postoperative analgesia was provided through epidural catheter. Analgesia was maintained by patient-controlled epidural analgesia pump, administering $5 \mathrm{cc} / \mathrm{hr} 0.125$ levobupivacaine $+2 \mathrm{mcg} / \mathrm{ml}$ fentanyl.

\section{The Assessment of Stress Markers}

In terms of stress response, for blood levels of cortisol, prolactin, glucose and insulin, blood was withdrawn for a total of 4 times into $4 \mathrm{ml}$ biochemistry vacuum tubes at the times indicated as follows: $\mathrm{T} 1=$ Immediately before induction of anesthesia, $\mathrm{T} 2=$ After surgical stimulus, $\mathrm{T} 3=$ Immediately after percutaneous dilation T4 $=$ Postoperative $24^{\text {th }}$ hour.

Measurement of Cortisol Levels: The samples were studied using the chemiluminescent method, by Immulite 2000 hormone auto-analyzer (Diagnostic Products Corporation, Los Angeles, USA). The normal values in diurnal rhythm are $5-25 \mathrm{mcg} / \mathrm{ml}$ in the morning and approximately half of the value of the morning time in the afternoon.

Measurement of Glucose Levels: The samples were studied using the enzymatic UV test (hexokinase method), by Olympus analyzer (Olympus Diagnostica $\mathrm{GmbH}$, Ireland). The normal value is between $75-115 \mathrm{mg} / \mathrm{dL}$.

Measurement of Prolactin Levels: Prolactin levels were measured using immunoassay method (Roche Diagnostics, Cobas Integra USA). Results were reported as ng / $\mathrm{ml}$.

Measurement of Insulin Levels: The samples were studied using solid phase chemiluminescence method (Diagnostic Products Corporation, Los Angeles, USA). 
Clinical Evaluation: The hemodynamic parameters of the patient were recorded during the operation (heart rate, systolic and diastolic blood pressure, oxygen saturation). To evaluate postoperative analgesia, visual analogue scale (VAS) was used. VAS score assessment was as follows; $0=$ no pain, $10=$ unbearable pain, pain intensity was evaluated on the scale from 0 10. Postoperative pain was evaluated at $0,1^{\text {st }}, 2^{\text {nd }}, 4^{\text {th }}, 8^{\text {th }}, 12^{\text {th }}, 24^{\text {th }}$, and $48^{\text {th }}$ hours by an anesthesiologist blinded to the study. Postoperative adverse effects such as nausea, vomiting, pruritus, headache, dizziness and numbness in the legs were recorded and treated, if necessary.

Sample Size: Based on the our preliminary study we aimed to detect a difference of $6 \mu \mathrm{g} / \mathrm{dl}$ in the cortisol concentration between groups and we found that the standard deviation (SD) was around $7 \mu \mathrm{g} / \mathrm{dl}$. Accordingly, we determined that the number of patients required in each group was 24 , based on power of $87 \%$ and alpha error of 0.05 by using Russ Lenth's Piface Java module.

Statistical Analysis: The Statistical Package for Social Sciences (SPSS Inc. Chicago, IL) 20.0 Program was used for statistical analysis. ANOVA for repeated measurements with Bonferroni verification was used for changes in intraoperative hemodynamic values together with metabolic and stress hormones. For comparison, Student's t test and Mann-Whitney U test for independent groups were used. $\mathrm{p}<0.05$ was considered statistically significant.

\section{RESULTS}

The demographic data together with the operative features (age, gender, weight, height, duration of the operation, length of hospital stay) of the groups were given in Table1. There were no significant differences in terms of demographic data and operative characteristics of the cases $(p>0.05)$. 
The preoperative and postoperative $24^{\text {th }}$ hour values of the groups for hematocrit, BUN and creatine were given at Table2. Intraoperative blood loss was assessed based on the preoperative and postoperative hematocrit values. Intraoperative blood loss was statistically significantly more in Group GA than Group GE. While there was no statistically significant difference between groups in terms of preoperative hematocrit values $(\mathrm{p}>0.05)$, the difference between Group GA and Group GE was statistically significant in terms of postoperative Htc values $(\mathrm{p}=0.011)$.

Data on the blood pressure and heart rate belonging to the groups were shown in Figure $1 \mathrm{a}, 1 \mathrm{~b}$ and $1 \mathrm{c}$. Blood pressure and heart rate were found to be statistically significantly lower in Group GE when compared to the baseline values in all time intervals that measurements were made. Additionally, in comparative evaluation of the two groups, in all time intervals except baseline measurement, blood pressure and heart rate were significantly lower in Group GE $(\mathrm{p}<0.05)$.

Plasma concentrations of stress hormones were presented in Table3. In Group GA, while the glucose concentration increased significantly following T2 and T3 when compared to baseline value $(\mathrm{p}<0.05)$, at T4 measurement time, it returned to its baseline level. In Group GE, no significant increase was observed when compared to baseline value ( $p>0.05)$.

In Group GA, following T2, T3 and T4, plasma cortisol concentrations were found to be significantly higher than the baseline value $(\mathrm{p}<0.05)$. However, in Group GE, no significant change was observed when compared to baseline. At T2, T3 and T4 measurement times, the cortisol levels were found to be significantly higher in Group GA when compared to Group GE $(\mathrm{p}<0.05)$.

In terms of blood insulin levels, there were no statistically significant differences between groups in all measurement times $(\mathrm{p}<0.05)$. In Group GA, the plasma insulin concentration showed statistically significant changes following T2, T3 and T4 when 
compared to baseline value $(\mathrm{p}<0.05)$. In Group GE, when compared to baseline value, no statistically significant change was observed in any measurement time $(\mathrm{p}>0.05)$.

The prolactin level increased significantly at T2 and T3 measurement times in Group GA when compared to Group GE ( $\mathrm{p}=0,002$ and $\mathrm{p}=0,003$ respectively) and returned back to its normal value at T4 measurement time. In Group GA, while the plasma prolactin level increased significantly following T2 and T3 when compared to baseline value $(\mathrm{p}<0.05)$, at T4 measurement time, it returned to its normal value. In Group GE, when compared to baseline value, no significant change was observed in any measurement time $(\mathrm{p}>0.05)$.

Data related to VAS scores were shown in Figure2. Pain scores were found to be statistically significantly lower in all measurement times following surgery in Group GE when compared to Group GA.

There were no significant differences between two groups when postoperative side effects were taken into consideration nausea, vomiting, pruritus, headache, dizziness and numbness in the legs.

\section{DISCUSSION}

When our data was compared to general anesthesia performed alone; epidural levobupivacaine added to general anesthesia was determined to decrease the stress hormone response, to provide better postoperative pain control, and to cause less bleeding. When intraoperative hemodynamic parameters were taken into consideration, heart rate and blood pressure were determined to remain statistically significantly higher in Group GA than Group GE which showed a more stable change. 
Intense epidural analgesia acquired by local anesthetics prevents the endocrine and metabolic response in pelvic and lower extremity operations. Epidural anesthesia and analgesia were shown to attenuate the neuroendocrine response related to surgical stress (11).

Epidural anesthesia reduced the response to surgical stress depending on the level of anesthesia and the site of surgical intervention. While increases in glucose and cortisol levels were prevented in lower abdominal interventions by an epidural block between T4-S5, a T6S5 block was not able to avoid it (2).

The importance of epidural anesthesia is manifested especially in reduction of the hidden endocrine stress response to a minimum in high-risk patients having co-morbidities such as arterial hypertension, coronary artery disease and diabetes mellitus (12).

Numerous studies that took place in the literature claimed that epidural anesthesia suppressed the stress hormone response and reduced the need for intraoperative opioid use $(13,14)$. Yuhong Li et al., in their study on 32 adult patients in whom nephrectomy was performed, showed that epidural ropivacaine added to general anesthesia suppressed both the intraoperative and postoperative stress hormone responses (15). J. Y. Hong et al. demonstrated similar results in their study on 60 adult patients in whom radical retropubic prostatectomy was performed with addition of epidural ropivacaine + sufentanil to general anesthesia (16).

Percutaneous nephrolithotomy (PNL) can be briefly described as management of urinary system stones by entering through a small hole created between the skin and kidney. PNL is the preferred treatment method for renal stones greater than $2 \mathrm{~cm}$, multiple stones or staghorn renal stones (17). Together with technological improvements in the field of medicine, percutaneous nephrolithotomy (PNL) became a method preferred to open surgery for management of renal stones as a noninvasive procedure. Parallel to increasing experience and improvements in surgical equipment in the last 30 years, significant developments took 
place in PNL technique. While undesired side effects of PNL and duration of hospital stay decreased, its success rate increased (18).

PNL procedure is generally performed under general anesthesia. But recently, PNL operations performed under epidural anesthesia, intravenous sedation and local anesthesia have been reported (19).

Regarding studies on patients undergoing PNL operation, we did not meet any study assessing effects of epidural anesthesia on intraoperative and postoperative surgical stress in the literature. In a study comparing open surgery with PNL (6), stress response was found to be manifested in both groups, with the magnitude of this response being less in PNL. In another study comparing open surgery with PNL, $24^{\text {th }}$ hour and $48^{\text {th }}$ hour cortisol levels were found to be statistically significantly lower in PNL group than open surgery group (20). These two studies were conducted under general anesthesia. However, our study is a study evaluating the stress response to combined epidural and general anesthesia during PNL surgery. In our study, the hormonal response related to surgical stimulus occurred in both groups. However, the hormonal response, manifested by increased levels of glucose, cortisol and prolactin could be more effectively suppressed during both intraoperative and postoperative periods in the group that epidural analgesia was used.

When we analyzed the studies comparing general and epidural anesthesia during PNL, we found out that postoperative pain, intraoperative bleeding, length of hospital stay and complications were the generally investigated parameters. Singh et al. (21) and Ünsal et al. (22) reached the conclusion that PNL with epidural anesthesia was a safe, effective and comfortable procedure. Tangpaitoon et al. (23) and Gönen et al. (24) compared epidural and general anesthesia in patients undergoing PNL. They found out that, while less pain scores, less need of postoperative analgesics and better patient satisfaction were present in patients with epidural anesthesia, no difference existed between general and epidural anesthesia in 
terms of decreasing $\mathrm{Hb}$ levels. Contrary to these two studies, in our study, the decrease between preoperative and postoperative hematocrit values was statistically more significant in Group GA when compared to Group GE. Since block level was above T4 in most of our cases, stress response was reduced and hemodynamic stability was provided. Therefore, the surgical procedure was continued with less blood pressure in epidural anesthesia group, resulting in the decrease of hematocrit being less than the general anesthesia group. This suggests the conclusion of less blood loss during surgery created with epidural anesthesia when compared to the general anesthesia group. We propose that the reason for obtained less pain scores with epidural anesthesia in our study may be our epidural intervention, which had been performed through T11-T12 space and had created sensorial block at the T6 level, especially suitable for renal surgery. The physiologic manifestations of stress should be reduced especially in patients with limited functions.

In hormonal response related to surgical trauma, the basic mechanism is the activation of hypothalamic-pituitary-adrenal axis and the sympathetic system by the afferent stimuli from the surgical field. Thus, catecholamines such as epinephrine and norepinephrine stress hormones such as cortisol, prolactin, $\mathrm{ADH}$ and $\mathrm{GH}$ are released. While these released hormones increase glucose production on one hand, they also lead to hyperglycemia by reducing glucose utilization, opposite to the effect of insulin, on the other hand.

Epidural anesthesia is an effective method for postoperative pain control; additionally, by administering local anesthetics into the epidural space, segmental sympathetic block is created. Due to their effects on postoperative morbidity and mortality, the effects of this temporary sympathetic blockade on cardiovascular, respiratory and other systems seem worth investigating. Thoracic epidural anesthesia is successfully used in heart, lung and major abdominal surgery (25). Early mobilization together with an analgesia maintained during 
mobility, provides suppression of stress response, early extubation, reduction in lung-related complications and rapid recovery in bowel functions.

\section{CONCLUSION}

The method of anesthesia that will be selected for percutaneous nephrolithotomy, which is characterized as a minimally invasive surgical procedure is also important. Combined epidural analgesia, added to general anesthesia, may be a comfortable anesthesia method especially in renal operations, with its low pain scores achieved by a sensory block above T6, its suppression of intraoperative and postoperative stress response and less pain scores in the early postoperative period. Our method of anesthesia and strategy for analgesia should be directed to the reduction of neuro-humoral response and avoidance of perioperative mortality and morbidity.

Conflict of Interest: None 


\section{REFERENCES}

1. Kehlet H, Holte K. Effect of postoperative analgesia on surgical outcome. $\mathrm{Br} \mathrm{J}$ Anaesth. 2001;87(1):62-72.

2. Desborough JP. The stress response to trauma and surgery. $\mathrm{Br} \mathrm{J}$ Anaesth. 2000;85(1):109-17.

3. Hall GM. The anaesthetic modification of the endocrine and metabolic response to surgery. Ann R Coll Surg Engl. 1985;67(1):25-9.

4. Kehlet H. Epidural analgesia and the endocrine-metabolic response to surgery. Update and perspectives. Acta Anaesthesiol Scand. 1984;28(2):125-7.

5. Matlaga BR, Assimos DG. Changing indications of open stone surgery. Urology. 2002;59(4):490-3; discussion 3-4.

6. Shen P, Wei W, Yang X, Zeng H, Li X, Yang J, et al. The influence of percutaneous nephrolithotomy on human systemic stress response, SIRS and renal function. Urol Res. 2010;38(5):403-8.

7. Malhotra SK, Khaitan A, Goswami AK, Gill KD, Dutta A. Monitoring of irrigation fluid absorption during percutaneous nephrolithotripsy: the use of $1 \%$ ethanol as a marker. Anaesthesia. 2001;56(11):1103-6.

8. Rao PN. Fluid Absorbtion During Urological Endoscopy. British Journal of Urology. 1987;60(2):93-9.

9. Sugai K, Sugai Y, Azuma Y, Tanaka Y, Miyazaki M. Vascular absorption of irrigation solution in percutaneous nephro-ureterolithotomy. Br J Anaesth. 1988;61(4):516-7.

10. Atici S, Zeren S, Aribogan A. Hormonal and hemodynamic changes during percutaneous nephrolithotomy. Int Urol Nephrol. 2001;32(3):311-4. 
11. Hadimioglu N, Ulugol H, Akbas H, Coskunfirat N, Ertug Z, Dinckan A. Combination of epidural anesthesia and general anesthesia attenuates stress response to renal transplantation surgery. Transplant Proc. 2012;44(10):2949-54.

12. Adams HA, Saatweber P, Schmitz CS, Hecker H. Postoperative pain management in orthopaedic patients: no differences in pain score, but improved stress control by epidural anaesthesia. Eur J Anaesthesiol. 2002;19(9):658-65.

13. Sibanda S, Hughes JM, Pawson PE, Kelly G, Bellenger CR. The effects of preoperative extradural bupivacaine and morphine on the stress response in dogs undergoing femoro-tibial joint surgery. Vet Anaesth Analg. 2006;33(4):246-57.

14. Goldmann A, Hoehne C, Fritz GA, Unger J, Ahlers O, Nachtigall I, et al. Combined vs. Isoflurane/Fentanyl anesthesia for major abdominal surgery: Effects on hormones and hemodynamics. Med Sci Monit. 2008;14(9):Cr445-52.

15. Li Y, Zhu S, Yan M. Combined general/epidural anesthesia (ropivacaine $0.375 \%$ ) versus general anesthesia for upper abdominal surgery. Anesth Analg. 2008;106(5):1562-5, table of contents.

16. Hong JY, Yang SC, Yi J, Kil HK. Epidural ropivacaine and sufentanil and the perioperative stress response after a radical retropubic prostatectomy. Acta Anaesthesiol Scand. 2011;55(3):282-9.

17. Ramakumar S, Segura JW. Renal calculi. Percutaneous management. Urol Clin North Am. 2000;27(4):617-22.

18. Opondo D, Tefekli A, Esen T, Labate G, Sangam K, De Lisa A, et al. Impact of Case Volumes on the Outcomes of Percutaneous Nephrolithotomy. European Urology. 2012;62(6):1181-7.

19. Kanaroglou A, Razvi H. Percutaneous nephrolithotomy under conscious sedation in morbidly obese patients. Can J Urol. 2006;13(3):3153-5. 
20. Aghamir SM, Mojtahedzadeh M, Meysamie A, Atharikia D, Izadpanah F, Sheikhvatan M. Comparison of systemic stress responses between percutaneous nephrolithotomy (PCNL) and open nephrolithotomy. J Endourol. 2008;22(11):2495-500.

21. Singh V, Sinha RJ, Sankhwar SN, Malik A. A prospective randomized study comparing percutaneous nephrolithotomy under combined spinal-epidural anesthesia with percutaneous nephrolithotomy under general anesthesia. Urol Int. 2011;87(3):293-8.

22. Ünsal A, Bozkurt O, Kara C, Bayındır M, Oğuz U, Değerli S. Percutaneus Nephrolitotomy with Epidural Anesthesia. Turkish J Urology. 2008;34(3):311-4.

23. Tangpaitoon T, Nisoog C, Lojanapiwat B. Efficacy and safety of percutaneous nephrolithotomy (PCNL): a prospective and randomized study comparing regional epidural anesthesia with general anesthesia. Int Braz J Urol. 2012;38(4):504-11.

24. Gönen M, Sarı R, Cicek T, Dursun M, Öztürk B. Tubeless percutaneous nephrolithotomy under spinal versus general anesthesia. Turkish J Urology. 2010;36(1):33-7.

25. Ulke ZS, Senturk M. Non-analgesic effects of thoracic epidural anesthesia. Agri. 2007;19(2):6-12. 
Table1: Demographic data and Operative Characteristics

\begin{tabular}{lccc}
\hline & Group GA (n=24) & Group GE (n=24) & p \\
\hline Gender (M/F) & $13 / 11$ & $13 / 11$ & \\
Age & $42.13 \pm 14.99$ & $44.79 \pm 14.83$ & 0.53 \\
Weight (kg) & $74.50 \pm 9.339$ & $73.88 \pm 9.835$ & 0.82 \\
Height (cm) & $169.92 \pm 9.75$ & $167.13 \pm 8.32$ & 0.29 \\
Duration of Operation (min) & $99.58 \pm 16.26$ & $104.83 \pm 19.77$ & 0.32 \\
Length of Hospital Stay (days) & $3.41 \pm 1.21$ & $3.29 \pm 1.16$ & 0.71 \\
\hline
\end{tabular}

All values were given as Mean \pm Standard Deviation

Table 2: Preoperative and postoperative $24^{\text {th }}$ hour values of Htc / BUN / Creatine

\begin{tabular}{llll}
\hline & Group GA $(\mathbf{n}=\mathbf{2 4})$ & Group GE $(\mathbf{n}=\mathbf{2 4})$ & P \\
\hline Preoperative Htc $(\mathrm{mg} / \mathrm{dl})$ & $44.6 \pm 4.53$ & $46.79 \pm 5.46$ & 0.138 \\
Postoperative Htc $(\mathrm{mg} / \mathrm{dl})$ & $36.49 \pm 5.93$ & $41.00 \pm 5.89$ & $0.011^{*}$ \\
Preoperative BUN & $15.16 \pm 3.84$ & $14.83 \pm 5.35$ & 0.809 \\
Postoperative BUN & $14.66 \pm 4.90$ & $12.70 \pm 4.11$ & 0.142 \\
Preoperative Creatine & $0.87 \pm 0.21$ & $0.88 \pm 0.22$ & 0.984 \\
Postoperative Creatine & $0.88 \pm 0.17$ & $0.96 \pm 0.23$ & 0.158 \\
\hline
\end{tabular}

All values were given as Mean \pm Standard Deviation

$* \mathrm{p}<0.05$ 
Table 3: Changes in Plasma Stress Hormone Levels

\begin{tabular}{|c|c|c|c|}
\hline & Group GA $(n=24)$ & Group GE $(n=24)$ & P (between groups) \\
\hline \multicolumn{4}{|c|}{ Glucose (mg/dl) } \\
\hline T1 & $95.00 \pm 24.14$ & $99.58 \pm 19.18$ & 0.470 \\
\hline $\mathbf{T} 2$ & $113.00 \pm 23.37 \dagger$ & $97.33 \pm 19.07$ & $0.014 *$ \\
\hline T3 & $126.66 \pm 22.31 \dagger$ & $90.20 \pm 11.63 \dagger$ & $0.000 *$ \\
\hline T4 & $95.91 \pm 19.51$ & $101.79 \pm 10.68$ & 0.202 \\
\hline \multicolumn{4}{|c|}{ Insulin (mU/I) } \\
\hline T1 & $8.81 \pm 4.36$ & $6.79 \pm 3.32$ & 0.078 \\
\hline $\mathbf{T} 2$ & $5.73 \pm 4.69 \dagger$ & $7.77 \pm 4.20$ & 0.120 \\
\hline $\mathbf{T 3}$ & $3.50 \pm 2.45 \dagger$ & $4.92 \pm 3.58$ & 0.115 \\
\hline T4 & $18.35 \pm 15.71 \dagger$ & $16.55 \pm 14.14$ & 0.678 \\
\hline \multicolumn{4}{|c|}{ Cortisol $(\mu \mathrm{g} / \mathrm{dl})$} \\
\hline T1 & $10.11 \pm 3.03$ & $13.12 \pm 6.17$ & 0.097 \\
\hline $\mathbf{T} 2$ & $16.08 \pm 5.73 \dagger$ & $14.36 \pm 8.62$ & $0.027^{*}$ \\
\hline T3 & $18.18 \pm 8.41 \dagger$ & $12.74 \pm 5.94$ & $0.013^{*}$ \\
\hline T4 & $19.38 \pm 7.27 \dagger$ & $12.90 \pm 8.20$ & $0.012 *$ \\
\hline \multicolumn{4}{|c|}{ Prolactin (ng/ml) } \\
\hline T1 & $10.84 \pm 3.21$ & $11.10 \pm 3.01$ & 0.776 \\
\hline $\mathbf{T} 2$ & $30.40 \pm 18.64 \dagger$ & $13.37 \pm 5.45$ & $0.001 *$ \\
\hline T3 & $45.44 \pm 34.34 \dagger$ & $19.89 \pm 14.11$ & $0.002 *$ \\
\hline T4 & $10.42 \pm 5.59$ & $12.86 \pm 15.70$ & 0.477 \\
\hline
\end{tabular}

All values were given as Mean \pm Standard Deviation

${ }^{*} \mathrm{p}<0.05$ when comparison was made between groups

$\dagger \mathrm{p}<0.05$ when intragroup comparison was made with the baseline value (T1) of the group

$\mathrm{T} 1=$ Immediately before induction of anesthesia, $\mathrm{T} 2=$ After surgical stimulus, $\mathrm{T} 3=$ immediately after percutaneous dilation $\mathrm{T} 4=$ Postoperative $24^{\text {th }}$ hour. 


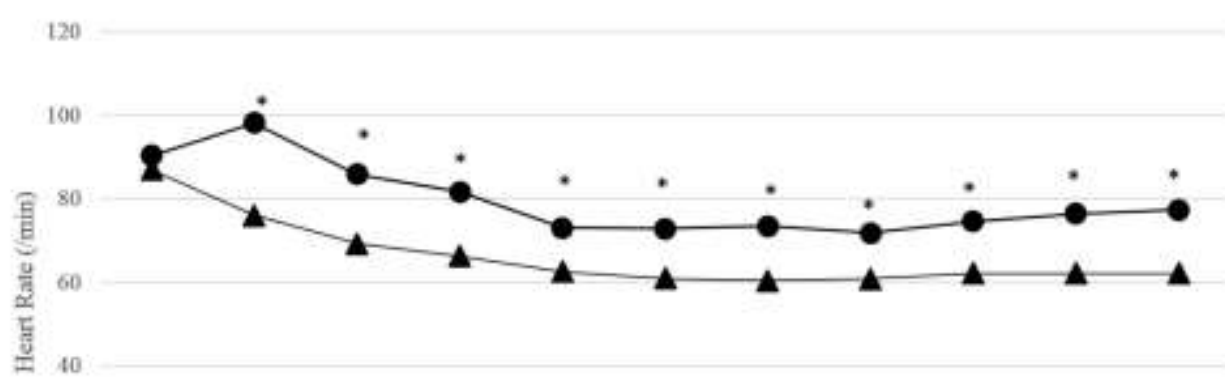

20

0

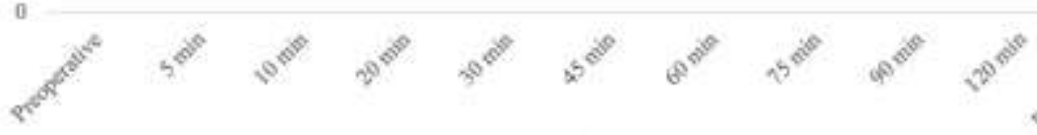

Times

$\rightarrow$ Group GA $\multimap$ Grong GE
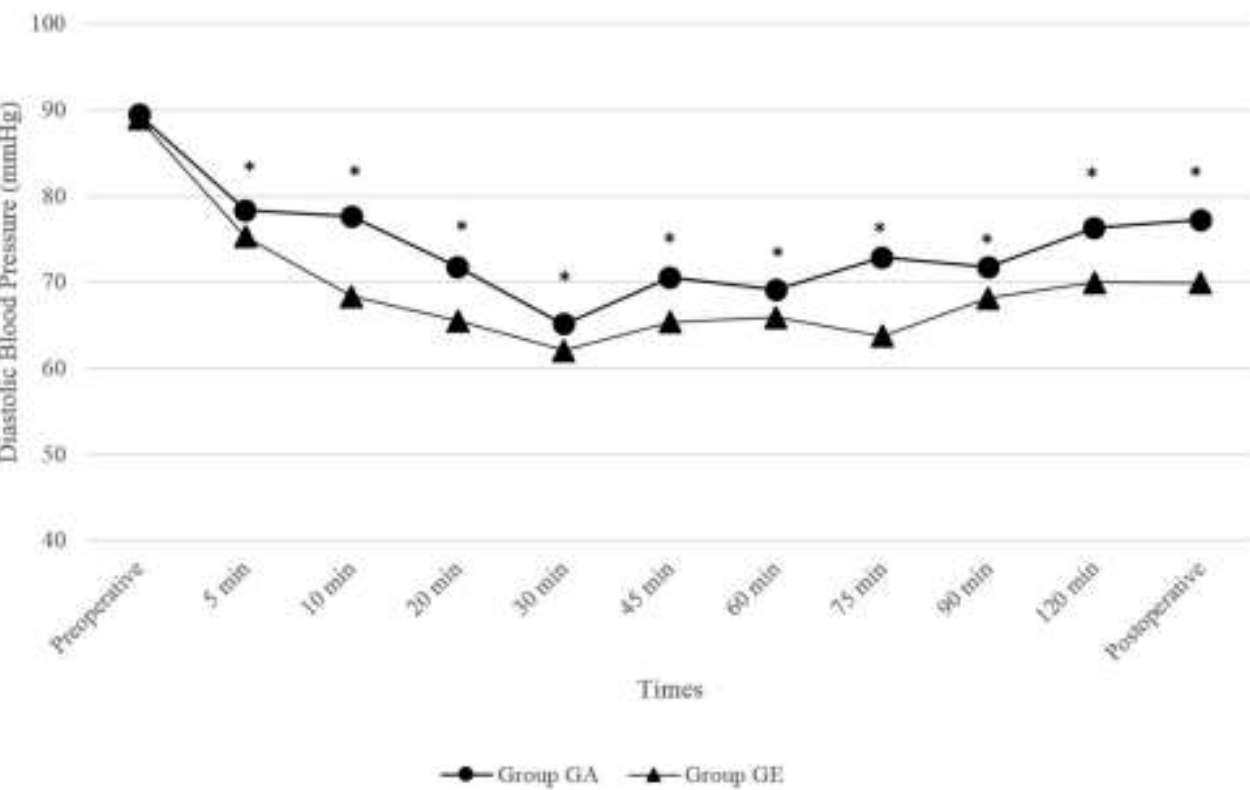

Fig. 1a, b, c: Changes in heart rate and blood pressures, ${ }^{*} \mathrm{p}<0,05$ 

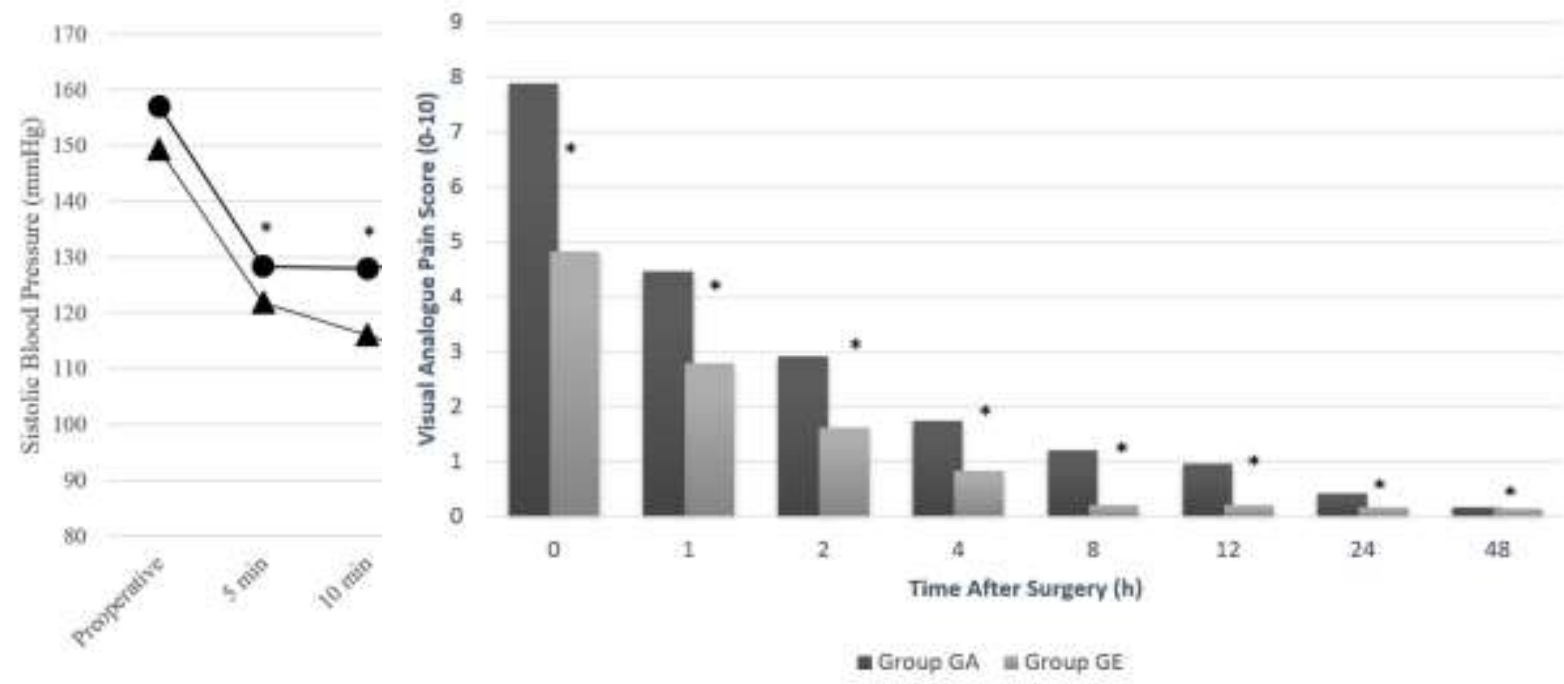

Fig. 2: Post Operative Pain Scores. ${ }^{*} \mathrm{p}<0.05$ when comparison was made between groups. Pain scores are statistically significantly lower in all measurement times following surgery in Group GE when compared to Group GA 